\title{
Analysis of the Effect of the Changes of Interest Rates on the General Profit Rate in China
}

\author{
Jianjun Zou, Jinshan Liu \\ College of Economics, Jinan University, Guangzhou, China \\ Email:yeszou@126.com
}

How to cite this paper: Zou, J.J. and Liu, J.S. (2017) Analysis of the Effect of the Changes of Interest Rates on the General Profit Rate in China. Modern Economy, 8, 726-744.

https://doi.org/10.4236/me.2017.85051

Received: April 11, 2017

Accepted: May 19, 2017

Published: May 22, 2017

Copyright $\odot 2017$ by authors and Scientific Research Publishing Inc. This work is licensed under the Creative Commons Attribution International License (CC BY 4.0).

http://creativecommons.org/licenses/by/4.0/

(c) (i) Open Access

\begin{abstract}
This article makes a macro-quantitative analysis on the relationship between the interest rate and the general profit rate, studies their interaction relationship in China from 1990 to 2014 with the Structural Vector Autoregressive (SVAR) model, and tests the erosion effect of the benchmark lending rate on the general profit rate. The results show that the changes of the benchmark lending rate have a significant negative effect on the general profit rate and the impulse response function analysis shows that the effect is enduring and lasts for 6 years; the variance decomposition results show that the changes of the benchmark lending rate have a high degree of explanation, and the final contribution rate is stabilized at approximately $33 \%$. With a correct understanding of the interaction relationship between the interest rate and the general profit rate, we can adjust the interest rate policy to slow down the decrease in the general profit rate and then mitigate the negative effect of the decrease on economic growth.
\end{abstract}

\section{Keywords}

Interest Rate, General Profit Rate, SVAR, Impulse-Response, Variance Decomposition

\section{Introduction}

China's economy has shifted from high-speed growth into medium-to-highspeed growth, which has become a new normal situation. The essence of the transformation is that China has moved from the high-speed potential growth rate stage into the medium-to-high-speed potential growth rate stage. As regards the change of the potential growth rate which is determined by the basic elements, not only the demand control but also the supply control should be considered. The interest rate is the core variable of both controls. How the interest rate affects the profit rate is the key to the policy transmission mechanism. 
The interest rate plays an important role in economic operations and is an important means of national macroeconomic policy regulation and control. From the macro perspective, the average profit rate, also known as the general profit rate, is the annual profit rate of the total social capital and also an important variable indicating the capital accumulation and the socio-economic growth. The increase in the general profit rate can improve the level of consumption and employment.

The theory and laws of general profit rate are the most essential laws to understand economic phenomenon and relationships. In particular, after the outbreak of the financial crisis in the US subprime mortgage market in 2007, the application of the theory can better explain the root causes and the function mechanism of the economic crisis. It will play an important role in the economic development to apply the theory of the interest rate and the general profit rate in interpreting the problems in China's economic and social development and further analyzing the internal mechanism behind the economic phenomenon.

This article focuses on the impact of the interest rate on the general profit rate as well as correct understanding of the interaction relationship between them. As regards the research methods, the article examined the relevant data to study the relationship with Structural Vector Autoregressive (SVAR) model. With the short-term recursive constraints set up in the model, the Granger causality test and the impulse response function were utilized to examine the interaction relationship with a view of analyzing the effect of the interest rate on the general profit rate. Meanwhile, the variance decomposition chart and the variance decomposition table were utilized to quantitatively analyze the relationship. The results of the quantitative analysis were further examined in respect of the current situation of the economic development in China.

\section{An Overview of Theoretical Evolutions and Researches}

\subsection{Theoretical Evolutions of the General Profit Rate}

In An Inquiry into the Nature and Causes of the Wealth of Nations (1776) [1], Adam Smith affirmed the theory of the general profit rate, claiming that the general profit rate existed in the society. David Ricardo inherited and further developed the opinion of Adam Smith in respect of the general profit rate, and pointed out in On the Principles of Political Economy and Taxation (1817) [2] that average profit existed in the society, that is, the same amount of capital obtains the same amount of profit, and took this view as the premise of his economic researches. In Principles of Political Economy (1848) [3], John Mill opined that there is a permanent minimum profit rate in the society; although the profit rate varies among different industries, the profit rate will tend to become the same when each factor has played a role and the general profit rate will come into being.

In Excerpts from James Mill's Elements of Political Economy (1843) [4], Marx's excerpted the essay on the profit rate of other industries mentioned by Mill. The profit rate of other industries is actually the general profit rate pro- 
posed by Marx. In Economic Manuscript of 1857-58 (1858) [5], Marx systematically elaborated the theory of general profit rate and he believed that the reason for its formation lies in the fact the profit rates of various production sectors are different. He believed that competitions are the prerequisite of the general profit rate. In Economic Manuscript of 1861-63 (1863) [6], Marx gave a more comprehensive exposition of the theory of general profit rate, which was an abstract concept proposed by Marx during this period. During the same period, Marx also put forward the conversion process of the general profit rate. In Capital (1867) [7], Marx presented a comprehensive and systematic exposition of general profit rate. He believed that the general profit rate is formed through competitions; that the prices of goods deviated from their values due to the existence of market competitions and averaged prices form among different sectors of the society; due to the influence of the supply and demand relationship, different profit rates come into being as the organic constitution of capital are different among different sectors; meanwhile, due to the role of the market, the capital will flow from less profitable sectors to more profitable sectors, and ultimately the profit rates of the production sectors tend to become the same.

\subsection{An Overview of the Researches of Chinese Scholars Since the 1990s}

Liu Diyuan et al. (1995) [8] argue that the general profit rate still exists in monopoly capitalism, the flow of capital still exists and the general profit rate tends to be become the same. Although monopoly causes prices to deviate from values in the short term, the profit rate of most production sectors will still average in the long term. According to the statistics from 1981 to 2009, Lu Baolin argued (2014) [9] that the general profit rate of China's real economy showed a downward tendency after excluding irregular changes and short-term changes in each year, and found that the short-term volatility of the general profit rate is mainly influenced by nonproductive expenditures. In particular, the general profit rates of China's real economy sectors are significantly related to the market-oriented reform and the reform of income distribution system in recent years. Yang Jinying et al. (2015) [10] found that, following the introduction of innovation factors in the general profit rate framework, the excess profit rate experienced significant changes and the general profit rate presents continuous fluctuations resulting from innovation, instead of showing a universal rule. Based on the estimation of the general profit rates of 38 countries from 1995 to 2009, Xu Chunhua (2016) [11] found that a significant decreasing tendency of the general profit rate of the sample countries at the average level and believed that the influence of the surplus value rate and the organic composition of capital on the general profit rate is of significant duality.

\subsection{Analysis of the Reasons for the Decrease in the General Profit Rate}

The reason for the decrease in the profit rate has been a hot issue in economics, 
and the following is a brief description and analysis of the four representative views.

1) Increase in the organic composition of capital

The scholars who insist on the theory of increase in the organic composition of capital, such as Mario (1987) [12], Anwar (1999) [13], etc. are called the orthodox school. The school believes that, as a result of the continuous development of capitalism, the mechanization leads to the increase in the organic composition of capital, which means the labor force is excluded from the production process. Although the surplus value grows with the increase in the organic composition of capital, the growth speed of surplus value is gradually decreasing due to the restrictions of the level of technological development and social development stage. As such, the influence of the organic composition of capital is greater than that of the increase in the surplus value, the result of which is the long-term downward tendency of the general profit rate.

\section{2) Profit squeezing}

The schcolars who insist on profit squeezing emphasize that the decrease in profits in national income is the most direct reflection of the decrease in profit rate, that is, the change in income distribution is the most important reason for the decrease in the profit rate, and if the profit can be broken down into the interest rate share $\frac{\pi}{Y}$ and the output share $\frac{Y}{K}$, that is $r=\frac{\pi}{K}=\frac{\pi}{Y} \times \frac{Y}{K}$, where $\pi$ represents the profit, $K$ represents the capital stock, $Y$ represents the net output; in this case, the profit rate is proportional to the ratio of profit share to the output share. Edward et al. (1979) [14] argued that the main reason for the decrease in the general profit rate is the decrease in the share of profits, and the decrease in the share of profits is mainly due to: profit squeezing resulting from the increase in labor level; the inhibitory effect on profitsresulting from the increase in productivity; the decrease in profits due to other factors.

3) Increase in nonproductive labor

Fred (1986) [15] and Simon (2004) [16] admitted that the organic composition of capital is an important reason for the decrease in the general profit rate, but they insisted that the increase in unproductive labor has a greater impact on the general profit rate. In specific historical periods, the increase in unproductive labor has become the most important cause for the decrease in the general profit rate.

4) Intensified competition

Gérard (2001) [17] argued that low-cost enterprises in Western Europe and Japanese companies entered the market in the early 1960s, and the global economic competitions were constantly intensified. In this case, excess capacity within capitalism and the issue of declining profit rate were highlighted. The over-competitive environment has made the enterprises less willing to conduct innovation. To be specific, new enterprises were willing to accept the level of profit rate before the application of new technology, while old enterprises lost the competitive advantage and the ability to add a price to the original costs. The 
combination of the two aspects deprived the manufacturing industry the premium capacity. With the nominal wage unchanged, the decrease in product price in essence increased the wages of workers, and the increase in the actual wage further reduced the profitability of the manufacturing industry. In conclusion, the decrease in the general profit rate was contributed to the external competitive environment.

\subsection{Explanation of the Decrease in the General Profit Rate from the Perspective of the Interest Rate}

Nowadays, China's domestic scholars conduct more researches on interest rate, while fewer researches on the general profit rate, and empirical researches combining both aspects is an innovation and trial.

The core of the decreasing tendency of the general profit rate is to emphasize that the long-term trend is declining, but it does not mean that the profit rate will decrease continuously or it provides an explanation in the short term for the level of the profit rate and the influence of economic fluctuations. According to Gao Feng (1991) [18], the economic trend is the long-term movement of economic variables in the same direction, so in terms of the general profit rate, so long as it moves toward a certain direction during most of the time, we will determine that it presents some kind of trend. Just like the price fluctuates around the value, the general profit rate fluctuates while maintaining the downward tendency [19].

Interest is a part of profit, the profit changes resulting from the market factors determines the changes of interest, the interest is adjusted by the profit, and the profit is determined by the profit rate, so the interest will inevitably be subject to the profit rate, that is, the long-term interest rate should be determined by the profit rate. If the average profit rate of the industries is lower than the economic and social interest rate, then the capital will flow out of the industrial field, and the capital cannot be effectively transformed from the monetary capital into the industrial capital. Eventually, the economy will recess and the asset prices will generates bubbles.

Despite the differences among the profit rates of different industries, the general profit rate still represents most of the individual profit rates. The external conditions of the accrual of interest are the coexistence of capital shortages and surpluses in the production process due to the characteristics of capital. Interest rate can affect the profit, and further affect the operations of the industrial capitals, that is to say, the interest rate has a regulation role on the production and operations of enterprises. "Profit for distribution" represents the increase in the use value during the implementation of the functions of monetary capital. As the change range of the residual value rate in a short period of time (one quarter or half a year) is small, that is, the total amount of surplus value is consistent and the changes of the lending rate are necessarily similar to those of the general profit rate. However, as the interest rate policy in China is frequently utilized as a tool for regulating the capital market and the macro-economy, some short- 
term inconsistencies occurred in certain years. The interest rate policy can lead to the phenomenon that "interest erodes profit", and further result in short-term fluctuations affecting the general profit rate. As the interest rate is the core variable for economic operations, the interest rate policy should be made carefully.

In conclusion, the main view is that the general profit rate presents a downward tendency, but is subject to the short-term influence of capital composition, competitions and other factors. This article argues that interest rate erodes profit in China, the lending rate affects the short-term fluctuation of the general profit rate, and a too high lending rate will exacerbate the decrease of the general profit rate. For small and medium-sized innovation and high-tech enterprises that heavily depend on loans, the erosion effect of high interest rates on their profits are apparent in particular. As such, the linkage between the monetary policy and the profit rate should be considered during the development of the interest rate policy. Suitable interest rates will be conducive to the development of the enterprises, and suitable interest rate policies and financial supports can increase the profit rates of the enterprises and facilitate the healthy economic development in China.

\section{An Empirical Analysis of the Effect of Interest Rate on the General Profit Rate}

The main tool for China's monetary policy is to adjust the benchmark deposit and lending rates. For a long period of time, the benchmark interest rate was mandatorily stipulated by the People's Bank of China, and the commercial banks did not have the autonomy to determine the lending rates which may fluctuate only within the range allowed by the Central Bank. The benchmark interest rate of China is exogenous, that is, the People's Bank of China does not adjust the deposit and lending rates for national professional banks and other financial institutions solely based on changes of the supply and demand relationship of monetary. Having further studied the Central Bank's development of the benchmark interest rates, we found that the interest rate adjustment is an outcome of the "multi-party game" of several government departments, including the State Council, the National Development and Reform Commission, the Ministry of Finance and the People's Bank of China. While the macro economy and the financial situation are among the causes for the adjustment of the benchmark interest rate, business costs and financial income are taken into account as well. Having considered the interests of several parties, the benchmark interest rates have transformed into a tool for the adjustment of the national income redistribution. On September 28, 1983, the State Council decided that the People's Bank of China should only exercise the functions of a central bank, and no longer conduct industrial and commercial credit and savings businesses from 1984. Meanwhile, before 1985, loans were divided into technological transformation loans and capital construction loans, the standards of which were not consistent with the prevailing loan standards. As such, the benchmark interest rate-related data analysis should start from 1985, and having considered that there was no 
one-year short-term loan interest rate before 1990, so the loan interest rate in this article are the weighted one year benchmark lending rate from 1990 to $2014^{1}$.

China does not officially publicize the calculated data of general profit rate, the domestic scholars conducted few researches, and the research outcome was rarely disclosed from 2012 to 2014. This article chooses the data from the author's own calculation and the relevant data. First, fixed capital stock, variable capital, total profit and other data were calculated using the perpetual inventory method, a mainstream method worldwide; secondly, the general profit rates of China from 1990 to 2014 were calculated based on the calculation formula of the general profit rate. Due to space constraints, this article does not elaborate the relevant calculation process and the data of the general profit rate.

\subsection{Comparison of the Changing Trends}

First, this article compares the data of the general profit rates with the data of the 1-year benchmark lending rates data of the same period (1990-2014) and then makes a corresponding comparison chart which is shown in Figure 1.

Figure 1 shows:

1) The data of the general profit rate data of China from 1990 to 2014 are generally consistent with the long-term downward tendency. All of the general profit rates during the period were below 30\%. The general profit rate was $17.91 \%$ in 1990 and $11.23 \%$ in 2014 and the corresponding calculation shows that the decrease rate of the general profit rate from 1990 to 2014 was $2.23 \%$ per year. The above-mentioned consistency is mainly attributable to the increase in the organic composition of capital resulting from the increased investment and technological progress of China's rapid economic development. Although the long-term trend of change is downward, it also presents significant fluctuations in certain short periods. The reason lies in the fact that, while the profit rate is bound to decrease in the long term, it appears to be complex and volatile as

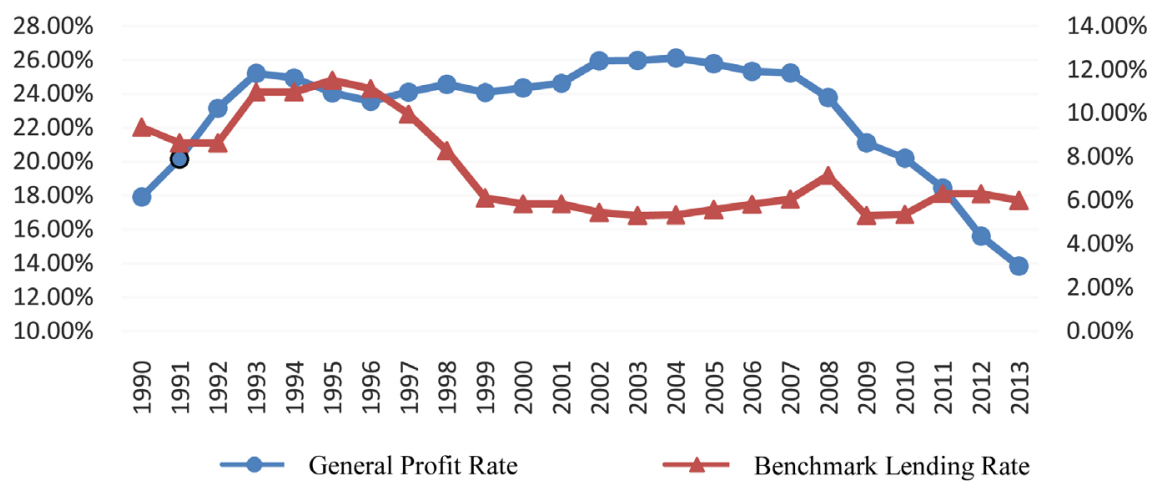

Figure 1. Comparison chart between the changing trends of the general profit rate and the 1-year benchmark lending rate in China from 1990 to 2014.

${ }^{1}$ The data were obtained from the website of the People's Bank of China (http://www.pbc.gov.cn/zhengcehuobisi/125207/125213/125440/125838/125888/index.html) and have been processed by the authors. 
there are many factors that can cause short-term fluctuations. The statistical software Stata13 was utilized for empirical analysis.

2) Except for individual years, the changes of the general profit rate and the 1 -year benchmark lending rate present a negative trend. As regards the changes in the same direction in certain years, the main cause are related to the purpose of macroeconomic regulation and control through the interest rate regulation, such as the stock market crash and the financial crisis of China's stock market from 2007 to 2008.

The most intuitive and direct observations in Figure 1 show that the changes of the benchmark interest rate have a significant negative effect on the general profit rate, which is an initial intuitive test. Next, this article conducts an empirical analysis on the data of the benchmark lending rates and the general profit rates from 1990 to 2014 by establishing the SVAR model and applying the Granger causality test, making the impulse response function analysis and applying the variance decomposition method, with the purpose of verifying whether the benchmark lending rate has a significant statistical negative effect on the general profit rate.

\subsection{Analysis of Data Smoothness}

1) Analysis of the smoothness of the general profit rate data

The data were analyzed through the autocorrelation and partial autocorrelation analysis and the Dickey-Fuller smoothness test respectively.

a) Autocorrelation graph and the partial autocorrelation analysis

Figure 2 shows that the autocorrelation coefficient of the general profit rate (p) exhibits the trailing characteristics. Figure 3 shows that the partial autocorrelation coefficient of the general profit rate $(\mathrm{p})$ exhibits a truncation tendency, that is, there is no significant partial autocorrelation in the third phase. However, the partial autocorrelation coefficient of the general profit rate (p) exhibits partial autocorrelation again in the 9th and 10th phase.

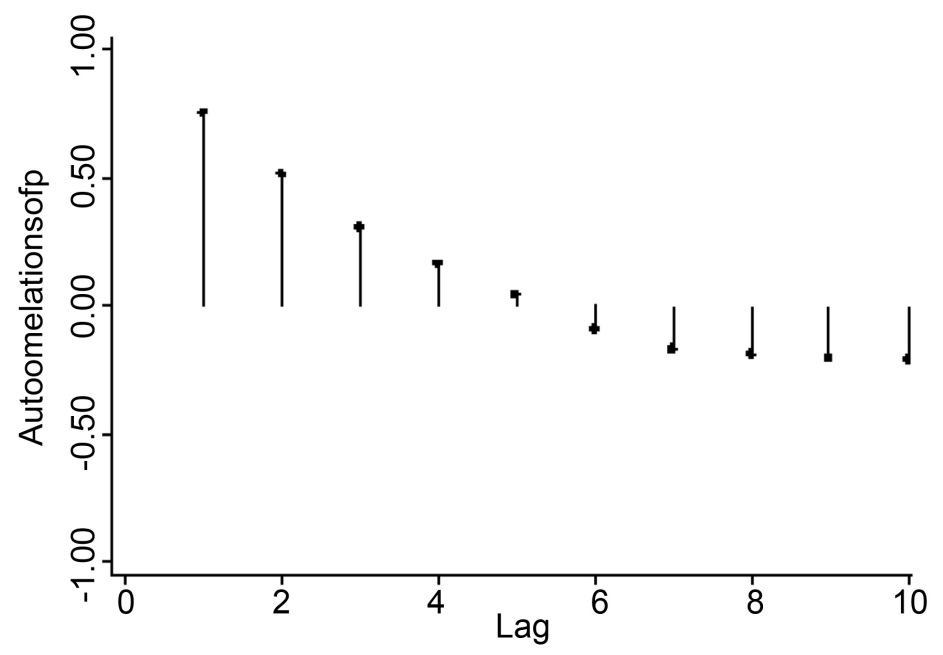

Figure 2. GPM (p) autocorrelation Graph. 


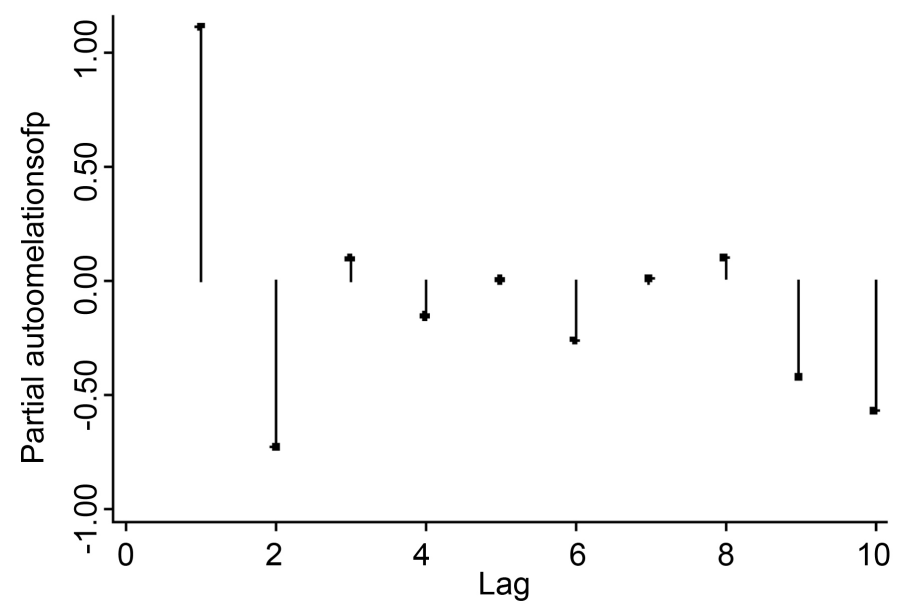

Figure 3. GPM (p) partial autocorrelation Graph.

b) Dickey-Fuller smoothness test

It can be seen from Figure 2 and Figure 3 that autocorrelation graph of the general profit rate $(\mathrm{p})$ exhibits the trailing characteristics, and the partial autocorrelation graph exhibits the truncation characteristics but the partial autocorrelation occurs after several lagging phases, so it is necessary to conduct further statistical analysis in order to analyze whether the general profit rate are stable. This article selected the ADF test to test the smoothness of the general profit rate, the results of which are shown in Table 1.

Table 1 shows that the general profit rate (p) is not a smooth time series and that the regression model cannot be directly established and further adjustment is required. In conclusion, the general profit rate (p) data is not smooth.

2) Analysis of the smoothness of the benchmark lending rate

Similarly, the data on the weighted average of the benchmark lending rate $(r)$ from 1990 to 2014 are analyzed through the autocorrelation and partial autocorrelation analysis and the Dickey-Fuller smoothness analysis respectively to analyze whether the data are smooth.

a) Autocorrelation graph and the partial autocorrelation analysis

Figure 4 shows that the autocorrelation coefficient of the benchmark lending rate (r) exhibits the trailing characteristics. Figure 5 shows that the partial autocorrelation coefficient of the benchmark lending rate ( $r$ ) exhibits a truncation tendency, but there is a high autocorrelation in the 10th phase.

b) Dickey-Fuller smoothness test

It can be seen from Figure 4 and Figure 5 that autocorrelation graph of the benchmark lending rate ( $r$ ) exhibits the trailing characteristics, and the partial autocorrelation graph exhibits the truncation characteristics but the partial autocorrelation occurs after 10 lagging phases, so it is necessary to conduct further statistical analysis in order to analyze whether the benchmark lending rate are stable. This article selected the ADF test to verify the smoothness of the benchmark lending rate, the results of which are shown in Table 2.

Table 2 shows that the benchmark lending rate $(r)$ is not a smooth time series 
Table 1. Test of the smoothness of the general profit margin.

\begin{tabular}{cccc}
\hline General profit rate Dickey-Fuller test & Number of samples & 25 \\
\hline Z-statistics & $\begin{array}{c}\text { 1\% Significance } \\
\text { level/critical value }\end{array}$ & $\begin{array}{c}5 \% \text { Significance } \\
\text { level/critical value }\end{array}$ & $\begin{array}{c}\text { 10\% Significance } \\
\text { level/critical value }\end{array}$ \\
1.170 & -2.508 & -1.717 & -1.321 \\
p-value of $Z$-statistics $=0.0622$. & & \\
\hline
\end{tabular}

Table 2. Test of the smoothness of the benchmark lending rate.

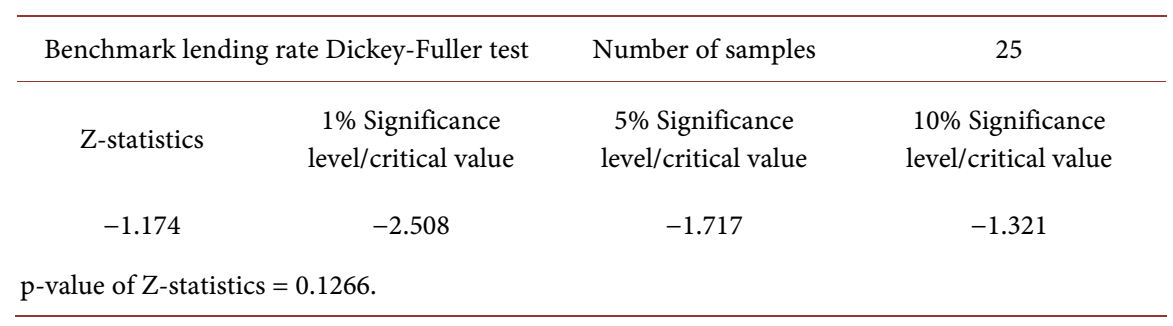

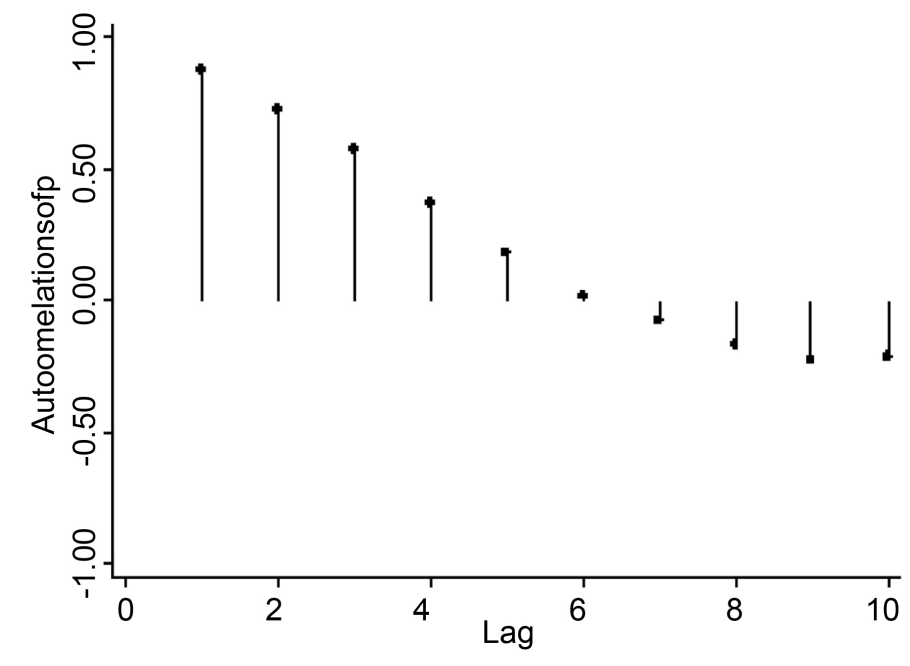

Figure 4. BLR (r) autocorrelation Graph.

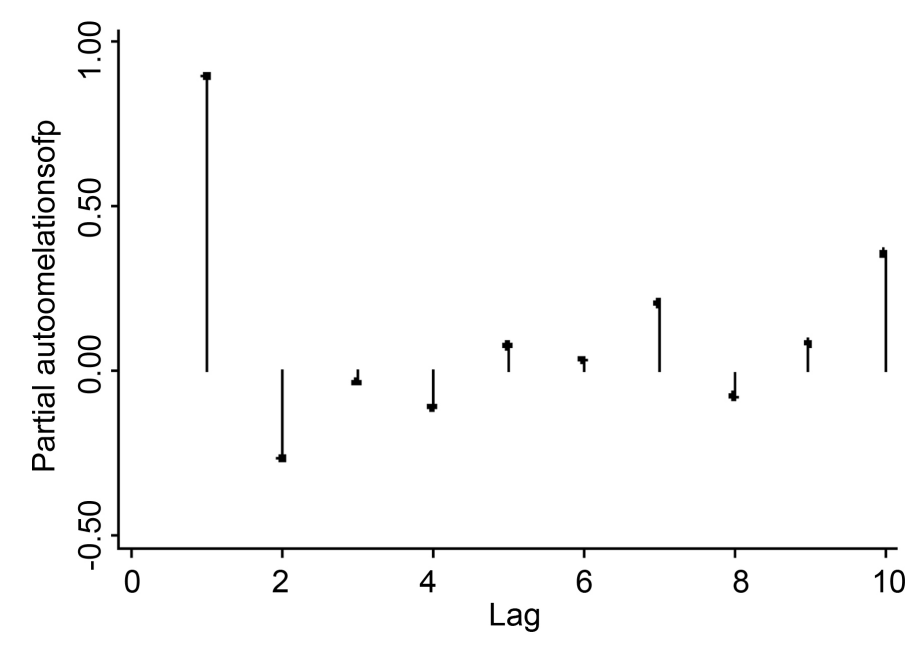

Figure 5. BLR(r) partial autocorrelation Graph. 
and that the regression model cannot be directly established and further adjustment is required.

In conclusion, the benchmark lending rate ( $r$ ) data is not smooth.

3) Adjustment of the data of the General profit rate and the benchmark lending rate

As neither the general profit rate nor the benchmark lending rate are smooth time series and an empirical analysis cannot be made directly, so difference computing were applied to both of them in order to get smooth data. After the respective difference computing, the (D.p) data of the general profit rate and the (D.r) data of the changes of the benchmark lending rate were obtained. Furthermore, the Dickey-Fuller test was conducted in order to test whether the data are stable, the results of which are shown in Table 3.

Table 3 shows that, after difference computing, the change data of the general profit rate (D.p) and the change data of the benchmark lending rate (D.r) are 0.045 and 0.0006 respectively, that is, after difference computing, both of them are smooth time series and both set of data are smooth. Without any "pseudo-regression" problem, the data meet the requirements of empirical analysis.

\subsection{The Choice of the Lag for the Model}

The choice of the lag is the key for the model, and a lag that is too large or too small will affect the accuracy of the model. In general, the increase in the lag can enhance the capability to explain the model, but the increase in the lag is at the expense of the freedom level. In order to find an optimal balance between the freedom level and the explanation capability of the model, the AIC criteria and other criteria proposed by Akaike (1974) were considered, and the optimal lag was selected based on comprehensive considerations, the details of which are set forth in Table 4.

Table 4 shows that Lag 1 is the final lag of the model, as proved by both the LR test and the ACI and SBIC criteria. Considering the above criteria, Lag 1 is the optimal lag for the model.

Table 3. Test of Smoothness of General Profit Rate (GPM) changes and the Benchmark Lending Rate (BLR) changes.

\begin{tabular}{cccc}
\hline \multicolumn{2}{c}{ GPM changes Dickey-Fuller test } & Number of samples & 25 \\
\hline Z-statistics & $\begin{array}{c}1 \% \text { Significance } \\
\text { level/critical value }\end{array}$ & $\begin{array}{c}5 \% \text { Significance } \\
\text { level/critical value }\end{array}$ & $\begin{array}{c}10 \% \text { Significance } \\
\text { level/critical value }\end{array}$ \\
-1.779 & -2.518 & -1.721 & -1.323 \\
p-value of Z-statistics $=0.0449$ & & 25 \\
\hline \multicolumn{2}{c}{ BLR changes Dickey-Fuller test } & Number of samples & $10 \%$ Significance \\
Z-statistics & $\begin{array}{c}1 \% \text { Significance } \\
\text { level/critical value }\end{array}$ & $\begin{array}{c}5 \% \text { Significance } \\
\text { level/critical value }\end{array}$ & -1.323 \\
-3.72 & -2.518 & -1.721 & \\
p-value of $Z$-statistics $=0.0006$ & &
\end{tabular}


Table 4. Choice of the lag for the model.

\begin{tabular}{ccccccccc}
\hline lag & LL & LR & df & p & FPE & AIC & HQIC & SBIC \\
\hline 0 & 128.659 & & & & $1.1 \mathrm{e}-08$ & -12.6659 & -12.6465 & -12.5663 \\
1 & 137.377 & $17.436^{*}$ & 4 & 0.002 & $6.8 \mathrm{e}-09^{*}$ & $-13.1377^{*}$ & $-13.0794^{*}$ & $-12.839^{*}$ \\
2 & 137.971 & 1.1868 & 4 & 0.880 & $9.7 \mathrm{e}-09$ & -12.7971 & -12.6999 & -12.2992 \\
3 & 142.583 & 9.2243 & 4 & 0.056 & $9.5 \mathrm{e}-09$ & -12.8583 & -12.7222 & -12.1613 \\
4 & 146.054 & 6.9416 & 4 & 0.139 & $1.1 \mathrm{e}-08$ & -12.8054 & -12.6304 & -11.9092 \\
\hline
\end{tabular}

\subsection{Structural Vector Autoregression Model}

In recent years, the vector autoregression (VAR) model has been widely utilized in the calculation of time series. Meanwhile, the VAR model is gradually moving towards binding categories, one of which is the SVAR model. The SVAR model can capture the immediate structural relationship between each variable and reflect the relationship between the variables more accurately than the VAR model. The theoretical basis of the SVAR model is the matrix changes of the VAR model. Considering the constraints between the variables, the dynamic simultaneous equations were transformed into a simplified model. The general form of the SVAR model can be expressed as a matrix:

$$
B_{0} y_{t}=c_{0}+B_{1} y_{t-1}+B_{2} y_{t-2}+\cdots+B_{p} y_{t-p}+\varepsilon_{t}
$$

where $c_{0}$ is an $n \times 1$ constant vector, $B_{i}$ is an $n \times n$ matrix, $\varepsilon_{t}$ is an $n \times 1$ error vector. $B_{i}$ reflects the intrinsic relationship among the variables that can be explained using economics, management and other methods. $\varepsilon_{t}$ is an n-dimensional disturbance and white noise.

The SVAR model with two variables can be expressed as:

$$
\left[\begin{array}{cc}
1 & B_{0 ; 1,2} \\
B_{0 ; 2,1} & 1
\end{array}\right]\left[\begin{array}{l}
y_{1, t} \\
y_{2, t}
\end{array}\right]=\left[\begin{array}{c}
c_{0 ; 1} \\
c_{0 ; 2}
\end{array}\right]+\left[\begin{array}{cc}
B_{1 ; 1,1} & B_{1: 1,2} \\
B_{1 ; 2,1} & B_{1 ; 1,2}
\end{array}\right]\left[\begin{array}{l}
y_{1, t-1} \\
y_{2, t-1}
\end{array}\right]+\left[\begin{array}{c}
\varepsilon_{1, t} \\
\varepsilon_{2, t}
\end{array}\right]
$$

where

$$
\Sigma=E\left(\varepsilon_{t} \varepsilon_{t}^{\prime}\right)=\left[\begin{array}{cc}
\sigma_{1} & 0 \\
0 & \sigma_{2}
\end{array}\right]
$$

Meaningful impacts can be achieved only when appropriate recognition conditions are assigned to the model. By estimating the simplified equation of the SVAR model, application of the estimated results and the constraints, the coefficient estimates and the structural impact of the model were obtained. As mentioned above, the benchmark lending rate of China is an outcome of a "multi-party game" among government departments and is affected by the general profit rate only in the long term. As such, this article adopts the lower triangular form when setting the constraints, and the short-term recursive constraints are set up as follows:

$$
B_{0}=\left[\begin{array}{ll}
1 & 0 \\
\alpha & 1
\end{array}\right], \varepsilon_{t}=\left[\varepsilon_{r}, \varepsilon_{p}\right], u_{t}=\left[u_{r}, u_{p}\right]
$$

Then the simplified perturbation vector and the structured perturbation vec- 
tor can be expressed as follows:

$$
\left[\begin{array}{l}
\varepsilon_{r} \\
\varepsilon_{p}
\end{array}\right]=\left[\begin{array}{ll}
1 & 0 \\
\alpha & 1
\end{array}\right]\left[\begin{array}{l}
u_{r} \\
u_{p}
\end{array}\right]
$$

1) The stability test and the residual normality test of the SVAR model

Before establishing the SVAR model, it is necessary to determine whether the model is stable. Having tested the absolute value of the characteristic root of the corresponding characteristic equation, the established SVAR model passed the stability test.

The residual normality test of the model was conducted. The results are shown in Table 5.

Table 5 shows that the significance of both the p-value of the model and the joint distribution is greater than 0.05 , indicating that the residuals of the model comply with the normal distribution, that is, the relation equation is reliable data production and the analysis result is of true value.

2) Granger causality test

The Granger causality test was utilized to analyze the causal relationship between the benchmark lending rate and the general profit rate. Granger causality defines a causal relationship from the forecast perspective, and the establishment of this causal relationship is based on the assumption that the future cannot predict the past. Assuming that variable $\mathrm{Y}$ is caused by variable $\mathrm{X}$, the changes of variable $\mathrm{Y}$ should be preceded by the changes of variable $\mathrm{X}$. As such, when variable $\mathrm{Y}$ returns the other variables (including the past value of $\mathrm{Y}$ ), assuming that the past and the lag values of $\mathrm{X}$ can significantly change the forecast of $\mathrm{Y}$, variable $\mathrm{Y}$ can be defined as the Granger cause of variable $\mathrm{Y}$. The test results are shown in Table 6.

The Granger causality test shows that the changes of the general profit rate is not the Granger cause for the changes of the benchmark lending rate, while the changes of the benchmark lending rate is the Granger cause for the general profit rate $(p=0.001)$, which means that lagged variable can predict changes of the

Table 5. Residual normality test.

\begin{tabular}{cccc}
\hline Jarque-Bera test & chi & df & Prob $>\mathrm{chi}^{2}$ \\
\hline Changes of the general profit rate & 0.371 & 2 & 0.83074 \\
Changes of the benchmark lending rate & 1.064 & 2 & 0.58752 \\
ALL & 1.435 & 4 & 0.83817 \\
\hline Skewness test & $\mathrm{chi}^{2}$ & $\mathrm{df}$ & ${\text { Prob }>\mathrm{chi}^{2}}^{2}$ \\
\hline ALL & 0.368 & 1 & 0.54430 \\
Changes of the benchmark lending rate & 0.091 & 1 & 0.76264 \\
Kurtosis test & 0.459 & 2 & 0.79499 \\
\hline Changes of the general profit rate & $\mathrm{chi}{ }^{2}$ & $\mathrm{df}$ & ${\text { Prob }>\mathrm{chi}^{2}}^{2}$ \\
Changes of the benchmark lending rate & 0.003 & 1 & 0.95459 \\
ALL & 0.972 & 1 & 0.32407 \\
\hline
\end{tabular}


Table 6. Analysis result of granger causality test.

\begin{tabular}{lccc}
\hline Original hypothesis & $\mathrm{chi}^{2}$ & $\mathrm{df}$ & Prob $>\mathrm{chi}^{2}$ \\
\hline $\begin{array}{c}\text { The changes of the general profit rate is not the } \\
\text { Granger cause for the changes of the benchmark } \\
\text { lending rate }\end{array}$ & 1.3496 & 1 & 0.245 \\
$\begin{array}{l}\text { The changes of the benchmark lending rate is not } \\
\text { the Granger cause for the changes of the general } \\
\text { profit rate }\end{array}$ & 10.409 & 1 & 0.01 \\
\hline
\end{tabular}

general profit rate.

3) Impulse response function

In order to understand the dynamic influence between the benchmark lending rate and the general profit rate, the impulse response function and the variance decomposition are utilized to give an explanation. The analysis of the impulse response function can make a deeper analysis of the interrelationship, the dynamic characteristics and duration of each economic variable and the variance decomposition can accurately analyze how much contribution the changes of the variables within the system or the impact of the structure can make to the endogenous variables.

The impulse response function describes the response of an endogenous variable to error terms. It can measure the impact of a change of one standard deviation in one variable from a disturbance on other endogenous variables, and can accurately describe the dynamic effect on the system when the model is impacted. The analysis results are shown in Figure 6.

As can be seen from Figure 6, the general profit rate has one standard deviation of positive impact, while the benchmark lending rate has almost no response and decays to 0 very swiftly. And when the benchmark lending rate gives a standard deviation positive impact, the general profit rate immediately has a negative response, continues to expand in the first phase, but begins to decrease in the second phase, and basically reaches 0 in the sixth phase, indicating that the effect of the benchmark lending rate on the general profit rate can generally last for about six years.

The results of the above-mentioned impulse response function of the SVAR model are basically consistent with the results of Granger causality analysis, that is, the changes of the general profit rate basically have no effect on the changes of the benchmark lending rate, while the changes of the benchmark lending rate have an apparent negative effect on the changes of the general profit rate.

It can be seen that the changes of the benchmark lending rate in China can affect the general profit rate, creating a negative relationship between them. The positive impact of the interest rate will cause a negative response of the general profit rate, that is to say, to raise the benchmark lending rate will reduce the general profit rate, which also proves from the perspective of macro analysis the above-mentioned expectation: interest erodes profit.

4) Variance decomposition

Although the above-mentioned impulse response function describes vividly 


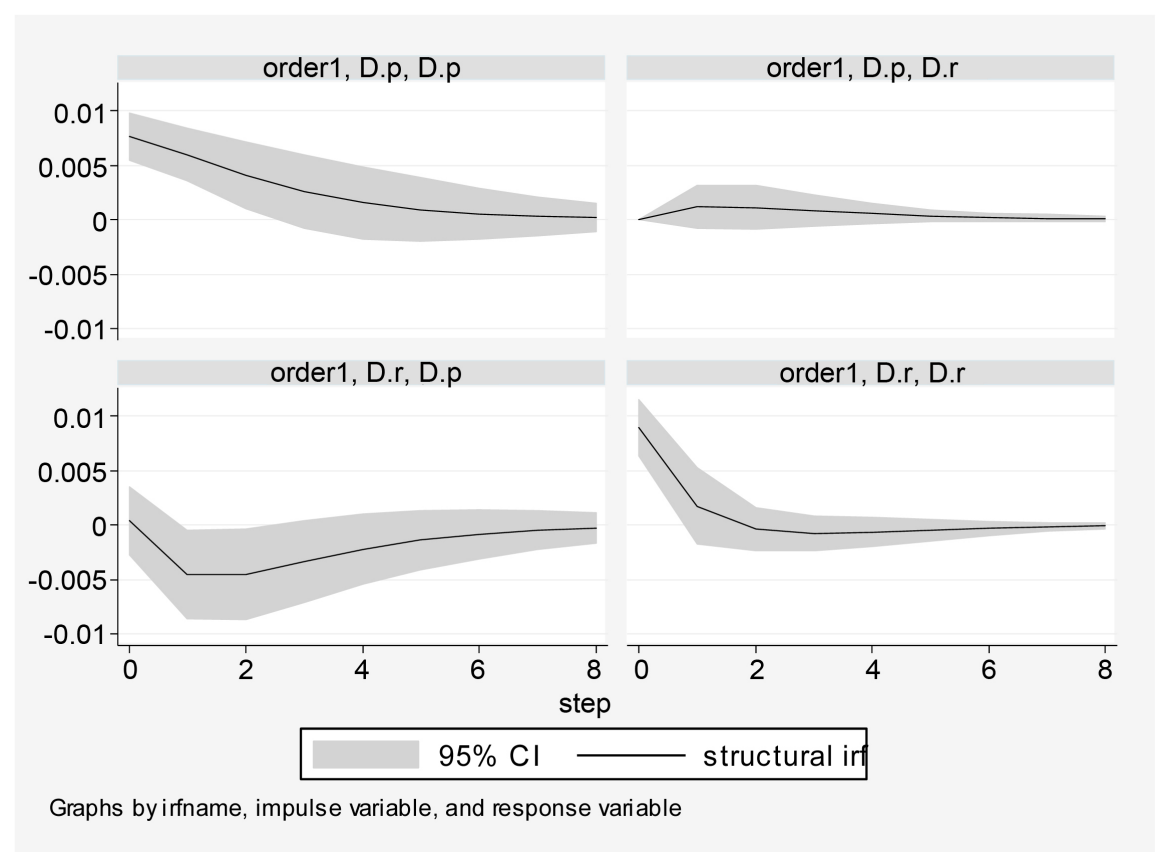

Figure 6. Impulse response function diagram.

the response of each variable to the impacts in the SVAR model, it is still necessary to conduct variance decomposition to quantitatively analyze the influence relationship between the variables. In order to further analyze the explanatory ability and the level of significance of the changes of the benchmark lending rate on the changes of the general profit rate, this article conducts variance decomposition of the impacts of the changes of the benchmark lending rate and the changes of the general profit rate respectively, and measures quantitatively the effects of variables on the impact. The results are shown in Figure 7 (Variance Decomposition Diagram) and Table 7 (Variance Decomposition Table).

As shown in Figure 7 and Table 7, judging from the variance decomposition results, the changes of general profit rate provide a weak explanation of the changes of benchmark lending rate, among which the first two provides almost no explanation, while the last one provides an explanation capacity of only $4.4 \%$. As such, the changes of the general profit rate offer a relatively small contribution to the changes of the benchmark lending rate. The results indicate that the changes of the benchmark lending rate in China are subject to relatively small impact from the changes of the general profit rate, but a certain degree of sensitivity does exist. As mentioned above, instead of being determined solely based on the supply and demand relationship of the monetary market, the adjustment of the exogenous benchmark interest rate depends on the government's judgment on the economic situation and involves multi-factors from the relevant departments. The changes of the general profit rate which represent the changes of the annual profit rate of the total social capital will affect the judgment on the present and future economy situation, thus affecting the determination of the relevant departments on the benchmark lending rate. Affected by the "game" and the transmission mechanism of the relevant government departments, the 


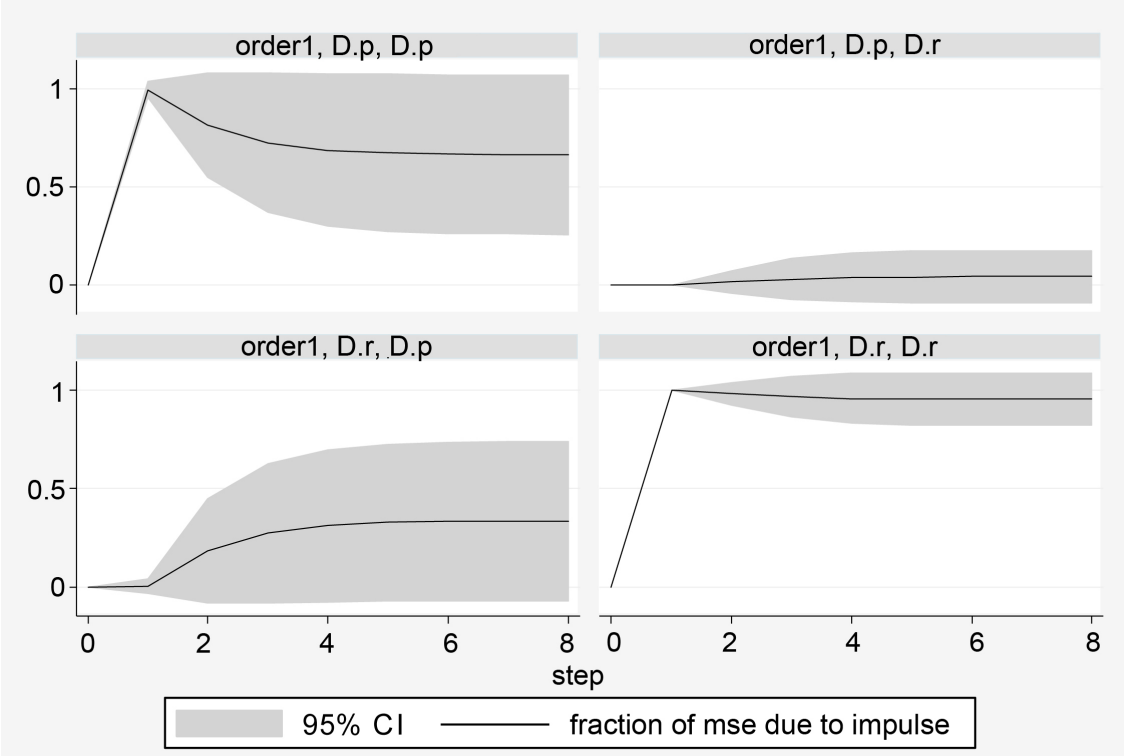

Graphs by irfname, impulse variable, and response variable

Figure 7. Variance decomposition diagram.

Table 7. Variance decomposition table.

\begin{tabular}{|c|c|c|c|c|c|c|c|}
\hline (1) step & (1) fevd & (1) lower & (1) upper & (2) step & (2) fevd & (2) lower & (2) upper \\
\hline 0 & 0 & 0 & 0 & 0 & 0 & 0 & 0 \\
\hline 1 & 1 & 1 & 1 & 1 & 0.002403 & -0.037569 & 0.042375 \\
\hline 2 & 0.983774 & 0.928131 & 1.03942 & 2 & 0.182473 & -0.085453 & 0.450399 \\
\hline 3 & 0.968847 & 0.864453 & 1.07324 & 3 & 0.273344 & -0.081824 & 0.628512 \\
\hline 4 & 0.96116 & 0.835005 & 1.08731 & 4 & 0.311128 & -0.0776 & 0.699856 \\
\hline 5 & 0.95796 & 0.824963 & 1.09096 & 5 & 0.326141 & -0.075093 & 0.727376 \\
\hline 6 & 0.956751 & 0.822293 & 1.09121 & 6 & 0.331846 & -0.073303 & 0.736995 \\
\hline 7 & 0.956319 & 0.821841 & 1.0908 & 7 & 0.333922 & -0.07211 & 0.739953 \\
\hline 8 & 0.956169 & 0.821894 & 1.09044 & 8 & 0.33465 & -0.071411 & 0.740711 \\
\hline (3) step & (3) fevd & (3) lower & (3) upper & (4) step & (4) fevd & (4) lower & (4) upper \\
\hline 0 & 0 & 0 & 0 & 0 & 0 & 0 & 0 \\
\hline 1 & 0 & 0 & 0 & 1 & 0.997597 & 0.957625 & 1.03757 \\
\hline 2 & 0.016226 & -0.039418 & 0.071869 & 2 & 0.817527 & 0.549601 & 1.08545 \\
\hline 3 & 0.031153 & -0.073242 & 0.135547 & 3 & 0.726656 & 0.371488 & 1.08182 \\
\hline 4 & 0.3884 & -0.087314 & 0.164995 & 4 & 0.688872 & 0.300144 & 1.0776 \\
\hline 5 & 0.04204 & -0.090956 & 0.175037 & 5 & 0.673859 & 0.272624 & 1.07509 \\
\hline 6 & 0.043249 & -0.091209 & 0.177707 & 6 & 0.668154 & 0.263005 & 1.0733 \\
\hline 7 & 0.043681 & -0.090796 & 0.178159 & 7 & 0.666078 & 0.260047 & 1.07211 \\
\hline 8 & 0.043831 & -0.090445 & 0.178106 & 8 & 0.66535 & 0.259289 & 1.07141 \\
\hline
\end{tabular}

95\% lower and upper bounds reported. (1) irfname $=$ order 1 , impulse $=$ D.r, and response $=$ D.r. (2) irfname $=$ order 1 , impulse $=$ D.r, and response $=$ D.p. $(3)$ irfname $=$ orderl, impulse $=$ D.p, and response $=$ D.r. $(4)$ irfname $=$ order 1 ,impulse $=$ D.p, and response $=$ D.p. 
formulation of the interest rate policy lags to a certain extent, which means that the results of the first two phases of the variance decomposition cannot explain.

The results of the variance decomposition persuasively proves that the changes of the benchmark lending rate has a strong capability to explain the changes of the general profit rate, that is, the changes of the benchmark lending rate will affect the changes of the general profit rate, which proves the abovementioned argument that interest erodes profit. As can be seen from Table 7, the changes of the benchmark lending rate have a relative significant effect on the general profit rate. At the beginning, there is a small contribution, and the contribution increases rapidly. The final contribution rate will stand at approximately $33 \%$ with a high explanation degree, indicating that the benchmark lending rate changes are relatively big contribution to the changes of the general profit rate. As such, the increase in the benchmark lending rate will gradually affect the decrease in the general profit rate, and the influence is obvious.

\section{Conclusions}

The SVAR model was utilized to study the interaction relationship between the benchmark lending rates and the general profit rates in China from 1990 to 2014. The short-term recursive constraints were set up in the form of matrix, and the Granger test and the impulse response function were utilized to test the mutual relationship between the two items, to verify whether the weighted benchmark lending rate has a statistically significant negative effect on the general profit rate, and the variance decomposition chart and the variance decomposition table were utilized to quantitatively analyze the relationship between the interest rate and the general profit rate. The results show that the benchmark lending rate has an erosion effect on the general profit rate; the changes of the benchmark lending rate have a significant negative effect on the general profit rate and the impulse response function analysis shows that the effect is enduring and lasts for 6 years; the changes of the general profit rate basically have no influence on the changes of the benchmark lending rate; the variance decomposition results show that the changes of the benchmark lending rate have a high degree of explanation of the changes of the general profit rate, and the final contribution rate is stabilized at approximately $33 \%$; on the other hand, the changes of the general profit rate have a low degree of explanation of the changes of the benchmark lending rate, with a small contribution degree, being $4.4 \%$ only.

The above conclusion shows that, as the benchmark interest rate of China is exogenous, it is inevitable that the general profit rate will decrease in the long term, which cannot be changed at people's subjective will. However, the decreasing tendency is subject to short-term fluctuations due to the influence of the interest rate policy. As interest erodes profit, the benchmark lending rate has an enduring negative effect on the short-term volatility of the general profit rate. In China, a too high benchmark lending rate will pull down the general profit rate of the whole society, while the modest low interest rate will facilitate the increase the general profit rate of the whole society. Nowadays, when the general 
profit rate presents a decreasing tendency, to lower the interest rate policy can slow down the pace of tendency, and further reduce the decrease in the general profit rate brought about by the negative effect of economic growth. The accurate understanding of the relationship between these two items can provide a reference basis for relevant government departments when making economic management decisions. To sum up, it should be cautiously considered whether to raise the interest rate or not. With the overall interest of the national economic operation taken into account, the current macroeconomic policy should be to control the monetary growth rate, stabilize the interest rate, optimize the credit structure, and strengthen the security system.

\section{References}

[1] Smith, A. (2008) An Inquiry into the Nature and Causes of the Wealth of Nations. Vol. 1 and 2, Chinese Version, Translated by Guo, D. and Wang, Y., Commercial Press, Beijing, 45-47.

[2] Ricardo, D. (2013) On the Principles of Political Economy and Taxation. Chinese Translation, Translated by Guo, D. and Wang, Y., Commercial Press, Beijing, 84-85.

[3] Mill (2013) Principles of Political Economy. Vol. 1 and 2, Chinese Version, Translated by Jin, D. and Jin, Y., Huaxia Publishing House, Beijing, 55-58.

[4] (1985) Marx, Engels, Karl Marx and Frederick Engels. Vol. 42, People's Publishing House, Beijing, 77-78.

[5] (1998) Marx, Engels, Karl Marx and Frederick Engels. Vol. 31: Economic Manuscripts of 1857-1858. Central Compilation \& Translation Bureau for Works of Marx, Engels, Lenin and Stalin. People's Publishing House, Beijing, 65-68.

[6] (2004) Marx, Engels, Karl Marx and Frederick Engels. Vol. 31: Economic Manuscripts of 1861-1863. Central Compilation \& Translation Bureau for Works of Marx, Engels, Lenin and Stalin. People's Publishing House, Beijing, 30-32.

[7] (2004) Marx. Capital. Central Compilation \& Translation Bureau for Works of Marx, Engels, Lenin and Stalin. People’s Publishing House, Beijing, 102-103.

[8] Liu, D. and Wang, C. (1995) Commentary on Cambridge Controversies (Mid). Finance and Economics, No. 1, 39-44.

[9] Lu, B. (2014) Dynamics of the Profit Rate of the Industrial Sectors in China: 19812009. Economics Study of Shanghai School, No. 2, 168-180.

[10] Yang, J. and Xiao, L. (2015) The Nature of Excess Profits and Its Effect on the General Profit Rate-The Expansion of Marx's Theory of Surplus Value Distribution. Marxism and Reality, No. 5, 94-100.

[11] Xu, J. (2016) The Performance of the Decreasing Rules of the General Profit Rate After the Crisis, Country Differences and Influencing Factors. World Economy, No. 5, 3-28.

[12] Mario, C. (1987) The Falling Rate of Profit and the Theory of Accumulation. International Journal of Political Economy, 17, 54-74.

[13] Shaikh, A. (1999) Explaining the Global Economic Crisis. Historical Materialism, 5, 103-144. https://doi.org/10.1163/156920699100414481

[14] Wolff, E.N. (1979) The Rate of Surplus Value, the Organic Composition and the General Rate of Profit in the U.S. Economy, 1947-67. The American Economic Review, 69, 329-341.

[15] Moseley, F. (1986) Estimates of the Rate of Surplus-Value in the Postwar United 
States Economy. Review of Radical Political Economics, 18, 168-189. https://doi.org/10.1177/048661348601800108

[16] Mohun, S. (2004) The Australian Rate of Profit 1965-2001. Journal of Australian Political Economy, No. 52, 82-112.

[17] Duménil, G. and Lévy, D. (2001) Costs and Benefits of Neoliberalism. A Class Analysis. Reviews of International Political Economy, 4, 578-607. https://doi.org/10.1080/09692290110077593

[18] Gao, F. (1991) Capital Accumulation Theory and Modern Capitalism. Nankai University Press, Tianjin, 34.

[19] Wang, T. (1988) The Long-Term Trend of the Changes of the General Profit Rate. Journal of Nankai University, No. 4, 18-24.

Submit or recommend next manuscript to SCIRP and we will provide best service for you:

Accepting pre-submission inquiries through Email, Facebook, LinkedIn, Twitter, etc. A wide selection of journals (inclusive of 9 subjects, more than 200 journals)

Providing 24-hour high-quality service

User-friendly online submission system

Fair and swift peer-review system

Efficient typesetting and proofreading procedure

Display of the result of downloads and visits, as well as the number of cited articles

Maximum dissemination of your research work

Submit your manuscript at: http://papersubmission.scirp.org/

Or contact me@scirp.org 